\title{
Effect of Body Hair Removal on Female Sexual Function \\ I.Younis ${ }^{1}$, M.A.Ibrahim ${ }^{2}$ and A.AAbd Alrahman ${ }^{3}$
}

${ }^{1}$ Professor of Dermatology, Venereology and Andrology Dept., Faculty of Medicine, Benha Univ., Benha, Egypt

${ }^{2}$ Lecturer of of Dermatology, Venereology and Andrology Dept., Faculty of Medicine, Benha Univ., Benha, Egypt

${ }^{3}$ (M.B.B.CH), Faculty of Medicine, Tanta Univ., Tanta, Egypt

E-Mail: dr_asmaaderma87@gmail.com

\begin{abstract}
Body hair is a sign of sexual maturity for both women and men, but in women femininity is actually associated with a lack of body hair. women in ancient Egypt and classical Greece may have removed some or all of their body hair and grooming pubic hair may have been considered a feature of women's sexual attractiveness. woman with body hair was seen as less sexually attractive, sociable and intelligent, and more masculine, than the same woman without body hair.

Evaluate the impact of removal of body hair on various aspects of female sexuality. a self-report questionnaire designed by the authors guided by the female sexual function index (Rosen et al, 2000). The aim of the study and the details of the questionnaire were explained to the women before taking their informed consent. Participants were 222 women recruited from those attending the Dermatology and Andrology outpatient clinics at El-menshawy General Hospital, Tanta. Increase all sexual function after body hair removal.

The present study findings indicate that sexual functions as desire, lubrication, orgasm improve after body hair removal in women .Several factors affect female sexual function after hair removal as circumcision, education, occupational status and site of hair removal.
\end{abstract}

Keywords: Female sexual function, Hair removal, Methods of hair removal.

\section{Introduction}

Women's total removal of their body hair has been referred to as "body hairlessness" and described as a "new norm" for women in the world that has occurred over the past decade, with possible clinical implications [1].

However, as body hair styles and removal practices have rarely been documented, it is questionable to what extent women's total removal of their body hair is either new or normative. From artistic renderings of nude women, limited scientific literature, and survey data, it is clear that the extent to which women have removed or groomed their body hair has varied by historical time and place [2]. For example, art and artifacts suggest that women in ancient Egypt and classical Greece may have removed some or all of their body hair (in Greece, by plucking or singeing with a lamp) and that groomed pubic hair may have been considered a feature of women's sexual attractiveness [3].

Women who resisted shaving body hair felt negatively evaluated as dirty or gross [4] Many women also judged other women who did not remove body hair as less sexually attractive, intelligent, sociable, happy, and positive compared to hairless women [5]. Men also negatively evaluated women who did not remove body hair [6].

Any visible body hair unacceptable for any woman [7]. Body hair removal often begins at or around puberty when hair may grow more thickly. Reasons provided for hair removal link hairlessness to attractiveness, femininity, cleanliness, sensation, others' preferences, and reasons of conformity to social norms [8] .

\section{Material and methods}

The current study is a cross sectional study. The subjects of this study were married women of different ages and cultures.

After taking the approval of the Ethical Committee and Dermatology \& Andrology department in Benha University, the study proceeded as follows: the tool of the study was a self-report questionnaire designed by the authors guided by the female sexual function index .

The aim of the study and the details of the questionnaire were explained to the women before taking their informed consent.

Participants were 222 women recruited from those attending the Dermatology and Andrology outpatient clinics at El-menshawy General Hospital,Tanta in the period between April 2019and October 2019.

\subsection{Statistical analysis}

Data were fed to the computer and analyzed using IBM SPSS software package version 20.0. (Armonk, NY: IBM Corp) Qualitative data were described using number and percent. Significance of the obtained results was judged at the $5 \%$ level.

\section{Results and discussion}

Table (1) Data of hair removal $(n=222)$.

\begin{tabular}{lll}
\hline & $\mathbf{N}$ & \% \\
\hline Method of hair removal & & \\
Shaving & 75 & 33.8 \\
Waxing & 50 & 22.5 \\
Use of sweet & 64 & 28.8 \\
\hline
\end{tabular}




\begin{tabular}{lcc}
\hline Table (1) Continue & & \\
\hline Laser & 33 & 14.9 \\
Site of hair removal & & \\
Including the face & 6 & 2.7 \\
Pubic and axillary & 89 & 40.1 \\
Both & 127 & 57.2 \\
\hline
\end{tabular}

Table (2) Sexual activity among participants after hair removal $(n=222)$.

\begin{tabular}{|c|c|c|}
\hline & $\mathbf{N}$ & $\%$ \\
\hline \multicolumn{3}{|l|}{ Frequency } \\
\hline Daily & 1 & 0.5 \\
\hline 2-3 times per week & 99 & 44.7 \\
\hline Once per week & 95 & 42.6 \\
\hline Once or twice per month & 11 & 5.0 \\
\hline$<$ Once per month & 16 & 7.2 \\
\hline \multicolumn{3}{|l|}{ Spontaneous desire } \\
\hline Once per day & 59 & 26.6 \\
\hline 2-3 times per week & 11 & 5.0 \\
\hline Once per week & 84 & 37.8 \\
\hline Once per month & 68 & 30.6 \\
\hline \multicolumn{3}{|l|}{ Lubrication } \\
\hline Almost every time of sexual encounters & 50 & 22.5 \\
\hline$>1 / 2$ times of sexual encounters & 92 & 41.4 \\
\hline About half the times of sexual encounters & 45 & 20.3 \\
\hline$<1 / 2$ times of sexual encounters & 19 & 8.6 \\
\hline Rarely or almost never & 16 & 7.2 \\
\hline \multicolumn{3}{|l|}{ Difficulty of lubrication } \\
\hline Not difficult & 98 & 44.1 \\
\hline Slightly difficult & 49 & 22.1 \\
\hline Very difficult & 71 & 32.0 \\
\hline Rarely or almost never & 4 & 1.8 \\
\hline \multicolumn{3}{|l|}{ Orgasm } \\
\hline Every time of sexual encounters & 26 & 11.7 \\
\hline$>1 / 2$ times of sexual encounters & 63 & 28.4 \\
\hline About half times of sexual encounters & 65 & 29.3 \\
\hline$<1 / 2$ times of sexual encounters & 43 & 19.3 \\
\hline Rarely or almost never & 25 & 11.3 \\
\hline \multicolumn{3}{|l|}{ Dyspareunia } \\
\hline$>1 / 2$ times of sexual encounters & 82 & 36.9 \\
\hline About half times of sexual encounters & 1 & 0.5 \\
\hline$<1 / 2$ times of sexual encounters & 95 & 42.8 \\
\hline Rarely or almost or never of sexual encounters & 44 & 19.8 \\
\hline \multicolumn{3}{|l|}{ Dyspareunia degree } \\
\hline High & 44 & 19.8 \\
\hline Moderate & 102 & 45.9 \\
\hline Low & 76 & 34.2 \\
\hline \multicolumn{3}{|l|}{ Sexual satisfaction } \\
\hline Very satisfied & 126 & 56.8 \\
\hline Moderately satisfied & 53 & 23.8 \\
\hline Dissatisfied & 43 & 19.4 \\
\hline
\end{tabular}

Table (3) Relation of hair removal to female sexual functions $(n=222)$.

\begin{tabular}{lcc}
\hline & $\mathbf{N}$ & $\mathbf{\%}$ \\
\hline Increase in desire after hair removal & 149 & 67.1 \\
Yes & 73 & 32.9 \\
No & & \\
\hline
\end{tabular}




\begin{tabular}{lcc}
\hline Table (3) Continue & & \\
\hline $\begin{array}{l}\text { Increase in frequency of orgasm after hair } \\
\text { removal }\end{array}$ & 172 & 77.5 \\
Yes & 50 & 22.5 \\
No & & \\
Increase in lubrication after hair removal & 198 & 89.2 \\
Yes & 24 & 10.8 \\
No & & \\
Increase of pain during vaginal penetration in the & & \\
day of hair removal & 44 & 19.8 \\
Yes & 178 & 80.2 \\
$\begin{array}{l}\text { No } \\
\text { Sexual activity after hair removal }\end{array}$ & \\
$\begin{array}{l}\text { Change to better } \\
\text { Change to worse }\end{array}$ & 192 & 86.5 \\
$\begin{array}{l}\text { No difference } \\
\text { Are there positive comments from your husband } \\
\text { on your body after removing body hair? }\end{array}$ & 0 & 0.0 \\
$\begin{array}{l}\text { Yes } \\
\text { No } \\
\text { Do you feel that you are more attractive after }\end{array}$ & 13.5 \\
removing body hair? & 149 & \\
Yes & 73 & 67.1 \\
No & & 32.9 \\
\hline
\end{tabular}

Body hair is a sign of sexual maturity for both women and men, but in women femininity is actually associated with a lack of body hair [9] Women who have excessive facial hair have a negative impact on quality of life [10].

Many researchers report that a woman with body hair was seen as less sexually attractive, sociable and intelligent, and more masculine, than the same woman without body hair [11].

The present study aimed to evaluate the impact of removal of body hair on various aspects of female sexuality.

Our study reported that the most common method used in hair removal is shaving $(33.8 \%)$, followed by sweet $(28.8 \%)$, then waxing $(22.5 \%)$ and the least is laser $(14.9 \%)$.This result agrees with [12],in their work almost all participants $(97.20 \%)$ reported having shaved some of their body hair, which makes shaving the most common depilatory method, followed by plucking (85.10\%), removal creams $(84.51 \%)$, and home waxing $(44.25 \%)$. Most of their participants had tried more than one method and only $0.59 \%$ had tried laser treatments. Razor and shaving cream for pubic hair grooming is the most common method of hair removal $(77.2 \%)$ as reported by [13].

Most commonly, women in the study of [12]depilated their under-arms $(98.67 \%)$ and legs $(93.66 \%)$, followed by the pubic area $(85.69 \%)$, eyebrows $(82.45 \%)$, and face $(41.30 \%)$.In our study regarding site of hair removal the commonest is removal of hair from both face, pubic and axillary $57.2 \%$, then pubic and axillary $40.1 \%$ and the least is face only $2.6 \%$.

The present study shows the effect of hair removal on different sexual items. Most of women have increase of all sexual functions as spontaneous desire, frequency of orgasm, lubrication during intercourse after body hair removal. The study shows that $86.5 \%$ of women feel that sexual activity changes to better, $67.1 \%$ receive positive comments from their husbands on their body after removing body hair and $76.6 \%$ of them feel more attractive after removing body hair. This result agrees with [14]who reported total female sexual function score and desire, arousal, lubrication and satisfaction subscale scores were significantly increased after hair removal compared to baseline scores. There is a prominent improvement in both sexual functions and sexual satisfaction of the participants after hair removal procedure. The increase in both sexual desire and sexual arousal might be attributed to the previous asseverations claiming that pubic hair removal provides increased aesthetic appearance and increased tactile sensitivity of the clitoris. Body satisfaction, self-esteem and sexual functions improve after total laser pubic hair removal in women [14].

In a study by [15] 2451 women between the ages of 18-65 were compared in terms of pubic hair removal type and sexual dysfunction, and found that women who had done total pubic hair removal had higher scores of total female sexual index, desire, arousal, lubrication, pain and sexual satisfaction than women with no hair removal and partial hair removal. Also [16] point to association between complete depilation and greater sexual activity.

Our present study shows that circumcised women have lower degree of desire, orgasm and lubrication after body hair removal than non-circumcised ones.This result agrees with [17] who revealed a significant association between female genital cutting and decline in the female sexual functions with significant difference between cases and controls in the total and individual FSFI domain scores. This decline is also manifested by the decreased frequency of sexual intercourse in cases compared to controls. Another study by [15] revealed no difference in the mean 
desire or pain score, while there were statistically significant differences in the arousal, lubrication, orgasm, and satisfaction, as well as the overall sexual function score between circumcised and control women.

The present study shows that working women had significant lower desire, lubrication and orgasm than housewives. This result agrees with [18] who found that female sexual dysfunctions were highly prevalent among working women.

In our study there was a high statistically significant correlation between different levels of education and desire, orgasm and lubrication ( $\mathrm{p} \leq 0.05)$.University education has the highest effect on desire, orgasm and lubrication than the lower education. There was no statistically significant effect on dyspareunia $(p>0.05)$ after body hair removal.This result agrees with [19] who indicated that women with higher educations would face sexual dysfunction less often.

The present study showed that there was a high significant correlation between the site of hair removal and desire, orgasm and lubrication $(\mathrm{p} \leq 0.05)$. Women who remove hair from both face, pubic and axilla have the highest desire, orgasm and lubrication. There was no statistically significant effect on dyspareunia $(p>0.05)$ after body hair removal.

[15] found that pubic hair removal was significantly associated with younger age,a greater interest in sex ,vaginal fingering, clitoral stimulation, having casual sex partners, more likely to have received cunnilingus in the past four weeks, and had a more positive genital selfimage and sexual function index scores.

\section{Conclusion}

The present study findings indicate that sexual functions as desire, lubrication, orgasm improve after body hair removal in women .Several factors affect female sexual function after hair removal as circumcision, education, occupational status and site of hair removal.

\section{References}

[1] MP.Labre,The Brazilian wax, New hairlessness norm for women.J .Commun Inq.vol.26,pp.113-132,2002.

[2] S.Ramsey , C.Sweeney, M.Fraser and G.Oades,Pubic hair and sexuality, A review.J.Sex.Med.vol.6,pp.2102-2110,2009.

[3]M.Kilmer,Genital phobia and depilation. J. Hell .Stud.vol.102,pp.104-12,1982.

[4]M. Toerien and S.Wilkinson ,Exploring the depilation norm,A qualitative questionnaire study of women's body hair removal. Qualitative. Res. Psych.vol. 1(1), pp.69-92,2004.

[5] SA.Basow and AC.Braman, Women and body hair,Social perceptions and attitudes. Psychol .Women. Q.vol.22(4), pp.637-645,1998.
[6] M.Tiggemann and C.Lewis,Attitudes toward women's body hair,Relationship with disgust sensitivity. Psychol .Women. Q.vol.28,pp.381-387,2004.

[7] M.Toerien , S.Wilkinson and P.Choi ,Body hair removal, The 'mundane' production of normative femininity. Sex Roles.vol.52,pp.399-406,2005.

[8]F.Breanne,Breaking body hair boundaries, Classroomexercises for challenging social constructions of the body and sexuality.Feminism \& Psychology.vol.22 (4),pp.482-506,2011.

[9]C.Hope,Aucasian female body hair and American culture.J.Am.Cult. vol.5,pp.93-99,1982.

[10]M.Lipton, L.Sherr, J.Elford, M.Rustin and W.Clayton. Women living with facial hair, The psychological and behavioral burden. J. Psychosom. Res.vol.61(2), pp.161-168,2006.

[11] M.Tiggemann and S.Hodgson, The Hairlessness Norm Extended, Reasons for and Predictors of Women's Body Hair Removal at Different Body Sites. Sex. Roles.vol.59, pp.889-897,2008.

[12]M.Toerien,S.Wilkinson and P.Choi Body hair removal, The 'mundane production of normative femininity. Sex Roles .vol.52,pp.399-406,2005.

[13]AL.DeMaria and AB.Berenson,Prevalence and correlates of pubic hair grooming among low-income Hispanic, black, and white women. Body Image.vol.10,pp.226-31,2013.

[14] M.Aydos ,S.Onen and E.Onen, The effects of total laser pubic hair removal on sexual functions, body perception and self-esteem in women. Eur. Res. J. (in press).

[15] D.Herbenick ,V.Schick ,M.Reece , S.Sanders and JD.Fortenberry,Pubic hair removal among women in the United States prevalence, methods, and characteristics.J.Sex.Med.vol.7,pp.3322-30,2010

[16]JL.Bercaw-Pratt,XM.Santos.J .Sanchez,L. AyensuCoker, DR .Nebgen, M .Boroughs and J .Thompson ,Correlates of body depilation, An exploratory study into the health implications of body hair reduction and removal among collegeaged men. Am .J .Mens Health.vol.8,pp.217-225,2014.

[17] S.Ismail, A. Abbas , D. Habib , H. Morsy ,M.Saleh and M.Bahloul ,Effect of female genital mutilation/cutting, types I and II on sexual function, casecontrolled study.Reproductive Health.vol. 14,pp.108,2017.

[18] K. Stamatiou,M .Margarit ,EI. Eftichia, EI. Nous ,DI. Dimitra Mistriot, R.Richard,and M.Saridi , Female Sexual Dysfunction (FSD) in Women Health Care Workers. Mater. Sociomed.vol.28(3),pp.178$182,2016$.

[19] BA.Fajewonyomi,EO.Orji,AO.Adeyem,Sexual dysfunction among female patients of reproductive age in a hospital setting in Nigeria. J. Health .Popul. Nutr.vol.25(1),pp.101-106. 